\title{
Dislodged Guidewire in the Descending Aorta and Iliofemoral Artery during Transfemoral Sheath Placement: Percutaneous Retrieval via Contralateral Femoral Artery-An Innovative Approach
}

\author{
Sumit Deb ${ }^{1} \quad$ Subhayan Mandal ${ }^{1} \quad$ Nilay Biswas $^{1} \quad$ Anik Giri Goswami $^{1} \quad$ Abdus Sajjad $^{1}$ \\ ${ }^{1}$ Department of Neurosurgery, Bangur Institute of Neurosciences, \\ Kolkata, India \\ Address for correspondence Dr. Subhayan Mandal, MS, FAGAI, MCh
PDT, Department of Neurosurgery, Bangur Institute of
Neurosciences, Kolkata, India (e-mail: subhayanmandal@gmail.com).
}

Indian J Neurosurg 2015;4:42-45.

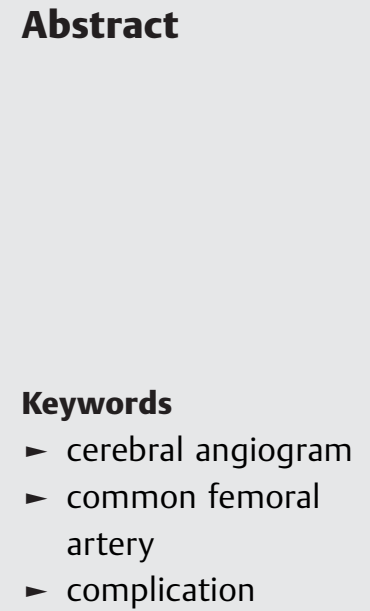

Abstract

A case in which a 0.038 -inch guidewire was inadvertently pushed into the common femoral-iliac and descending aorta, during sheath-guidewire placement, through the common femoral artery during cerebral angiogram is described here, and a successful retrieval system using a coronary guidewire is also described. A Boston Scientific MPXF $6 \mathrm{Fr}$ guiding catheter (Boston Scientific, Boston, Massachusetts, United States) shortened to $70 \mathrm{~cm}$ was advanced beyond the floppy tip of the guidewire through the left common femoral artery. A Cordis (Miami, Florida, United States) supersoft coronary guidewire of 0.014 -inch diameter, bent on itself through the middle so as to have an available $90 \mathrm{~cm}$, with the closed advancing tip splayed and bent at an angulation of 90 degrees to form a gooseneck, was advanced through the lumen of guiding catheter to seize the floppy tip of the guidewire acting like a snare and captivating it into the guiding catheter; and thereafter, the whole system was withdrawn en bloc.

\section{Introduction}

The transfemoral approach is currently popular for vascular access during cerebral angiogram and interventions. Arterial puncture is usually simple. A floppy tip guidewire is advanced through the puncture needle. Once the guidewire is placed intra-arterially and the placement is confirmed fluoroscopically, the needle is removed. The arterial sheath and dilator are passed over the guidewire after ensuring that the distal end of the guidewire is brought through the sheath-dilator complex and held by an assistant. Failure to hold the guidewire during one such procedure leads to the same being pushed into the common femoral artery. This report describes a successful percutaneous retrieval method via contralateral femoral artery and complication of angiography subsequently.

\section{Case Report}

A 55-year-old nondiabetic, nonhypertensive obese woman underwent a four-vessel cerebral angiogram for spontaneous subarachnoid hemorrhage. The right femoral artery was punctured, and during the passage of arterial sheath and dilator over the guidewire, the failure to hold the tip of the guidewire caused it to become dislodged and pushed it into the right common femoral artery. Under fluoroscopy, the floppy tip of the guidewire was found to lie in the descending aorta with the distal end being in the right femoral artery. To retrieve the dislodged guidewire, a Boston Scientific $6 \mathrm{Fr}$ Guider Softip XF Guiding Catheter, 6Fr (Boston Scientific, Boston, Massachusetts, United States) shortened to $70 \mathrm{~cm}$ was placed in the left femoral artery. The tip of the Guider Softip was advanced beyond the floppy tip of the guidewire. A published online March 21, 2015
DOI http://dx.doi.org/ 10.1055/s-0035-1549058. ISSN 2277-954X. (c) 2015 Neurological Surgeons' Society of India
License terms

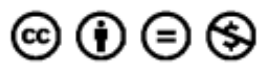




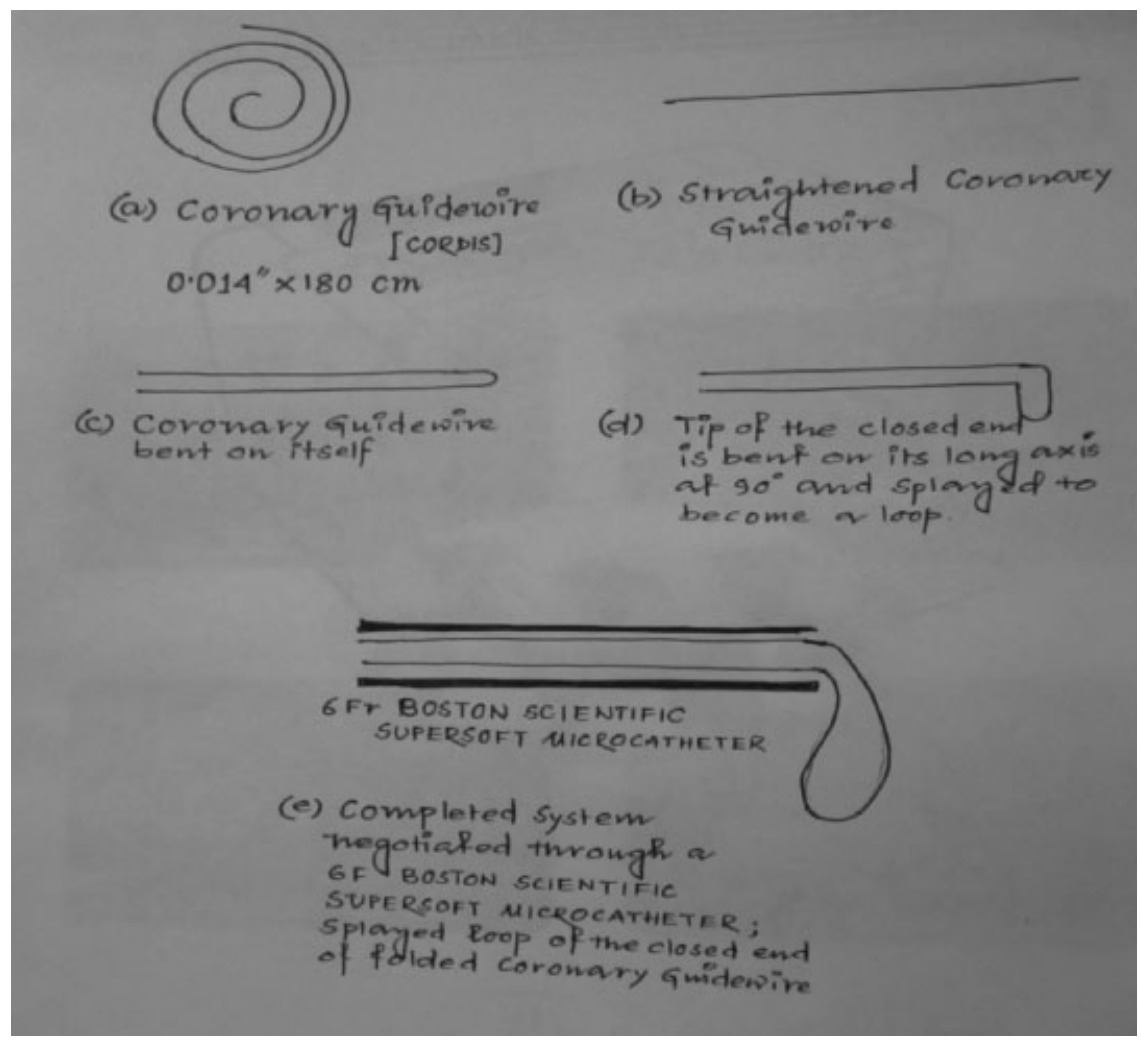

Fig. 1 Steps of making the retrieval system.

Cordis supersoft coronary guidewire of 0.014-inch diameter bent on itself at the middle, so as to have an available working length of $90 \mathrm{~cm}$, with the distal close tip bent an angle of 90 degrees on its axis, and splayed to look like a gooseneck snare loop (-Fig. 1), was advanced through the lumen of guiding catheter. Now after advancing the coronary wire beyond the floppy tip, the same was seized and captivated into the guiding catheter (-Figs. 2 and $\mathbf{3}$ ). Thereafter, the whole system was removed successfully en bloc (-Fig. 4). The cerebral angiogram was completed subsequently.

\section{Discussion}

Unmet complication is the cursed baby of advancing technologies. Dislodged guidewire is a serious and potentially life-threatening complication with reports of fatalities being up to $20 \%{ }^{1}$ when the complete wire is lost. Retained guidewire in the circulation causes complications such as thrombosis, emboli, and sepsis. Nonsurgical removal of the lost guidewire is the treatment of choice. ${ }^{2}$ Several methods for a dislodged broken wire have been reported such as a small-balloon catheter, a snare loop, the two-wire technique, and instruments used only beyond the coronary circulation such as grasping forceps and basket retrieval devices. $^{3-13}$ Snare loop wire or its modification was the most common technique used. ${ }^{2,3}$ Such snare loop systems are costly devices and may not be readily available. Because neurosurgeons are increasingly carrying out neuro interventional techniques; therefore, it is imperative that they familiarize themselves with such retrieval techniques. The complications caused by us was entirely avoidable, however, could have proven fatal.

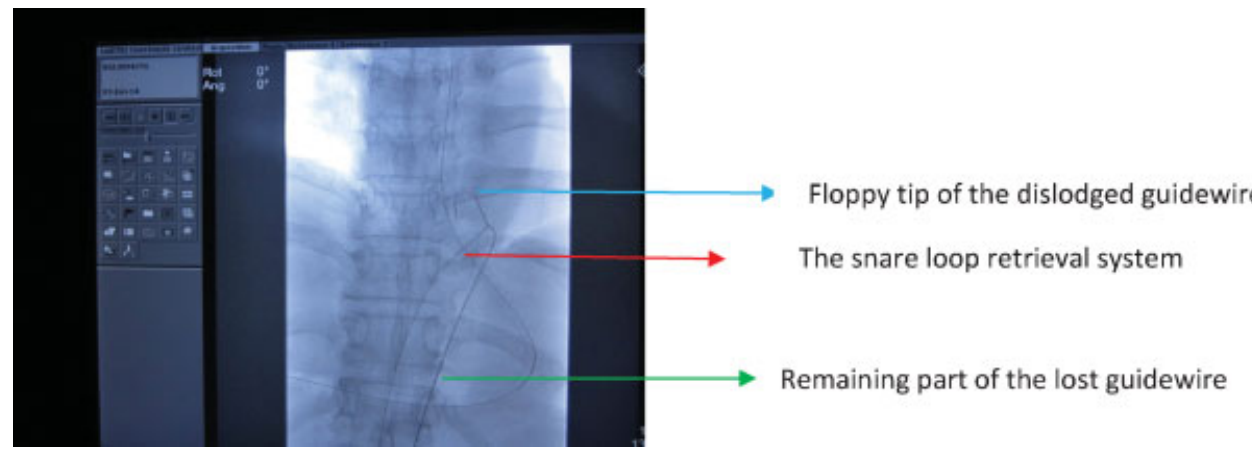

Fig. 2 The guidewire was being seized into the snare loop retrieval system. 


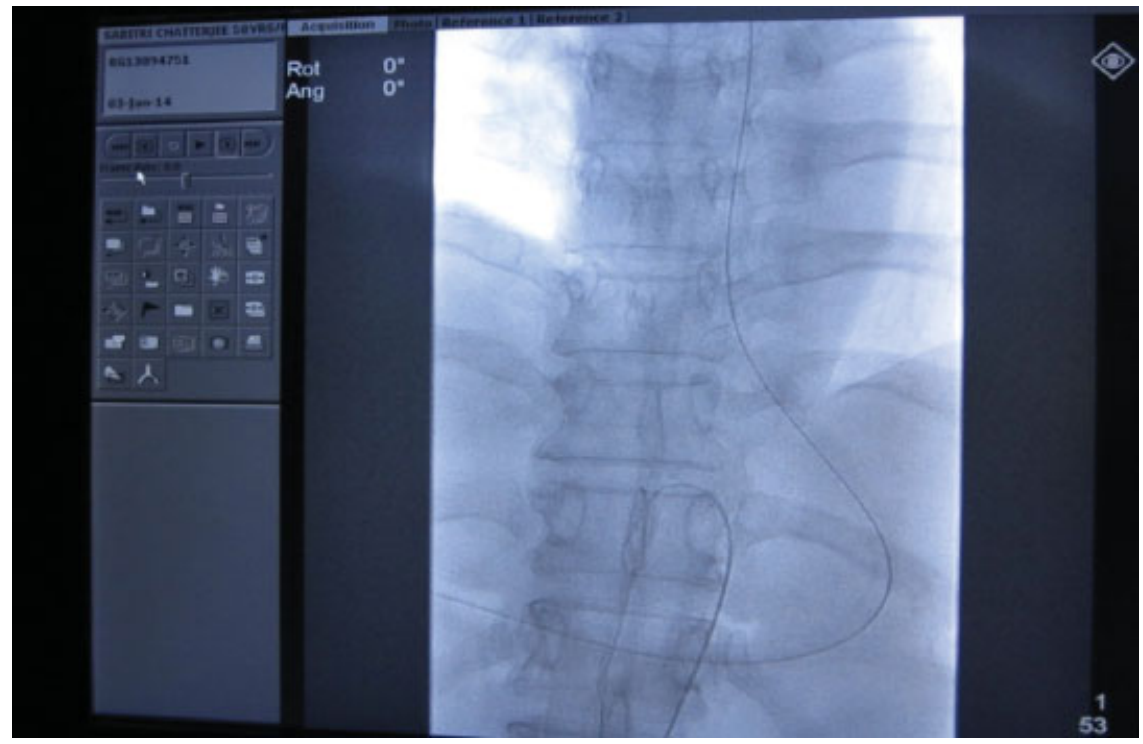

Fig. 3 The guidewire was captivated into the guiding catheter after being seized into the snare loop retrieval system.

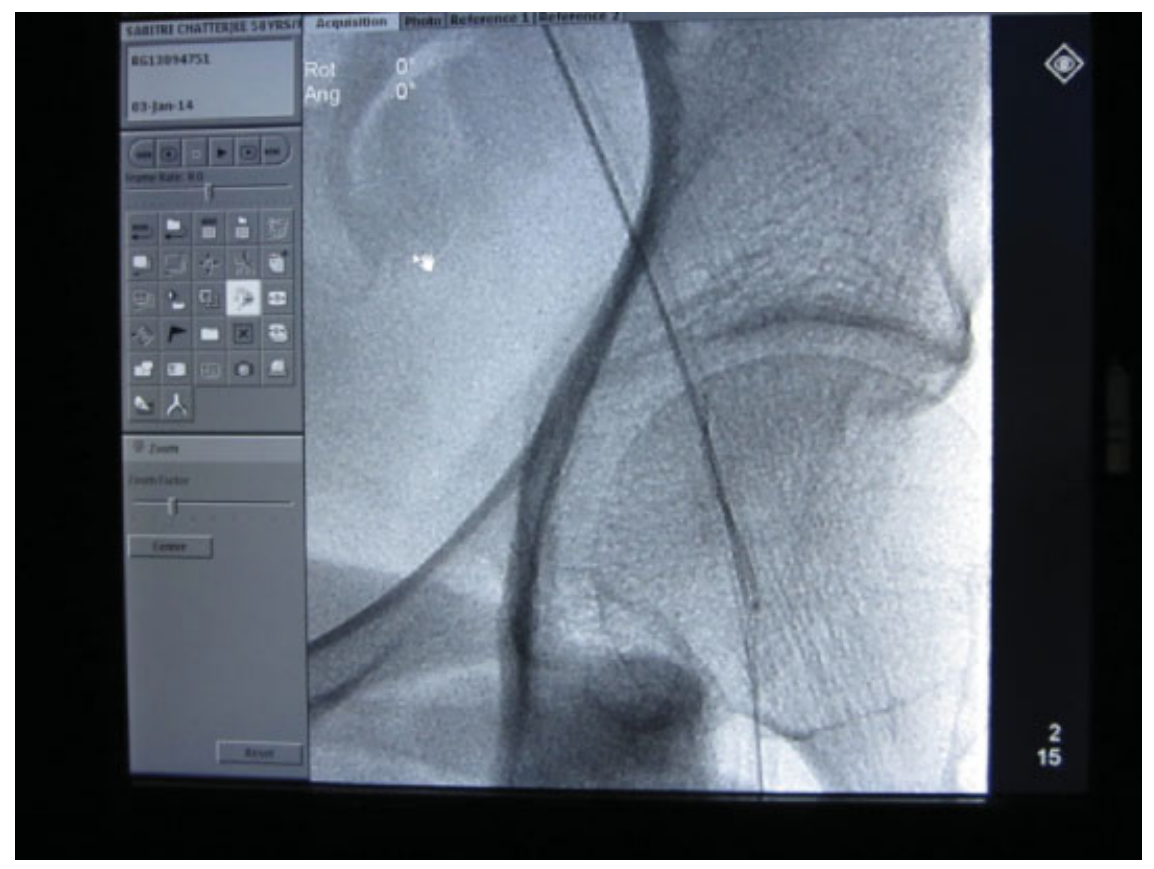

Fig. 4 The whole system was retrieved.

Source of Support

Nil.

\section{Conflict of Interest}

None.

\section{Acknowledgment}

The authors thank Tulyasys for technical editing.

\section{References}

1 Heberer M, Moser J, Dürig M, Harder F. Prospective study of complications of central venous catheters [in German]. Infusionsther Klin Ernahr 1984;11(5):254-261

2 Fisher RG, Ferreyro R. Evaluation of current techniques for nonsurgical removal of intravascular iatrogenic foreign bodies. AJR Am J Roentgenol 1978;130(3):541-548

3 Watson LE. Snare loop technique for removal of broken steerable PTCA wire. Cathet Cardiovasc Diagn 1987;13(1):44-49

4 Hartzler GO, Rutherford BD, McConahay DR. Retained percutaneous transluminal coronary angioplasty equipment 
components and their management. Am J Cardiol 1987;60(16): 1260-1264

5 Mintz GS, Bemis CE, Unwala AA, Hadjimiltiades S, Kimbiris D. An alternative method for transcatheter retrieval of intracoronary angioplasty equipment fragments. Cathet Cardiovasc Diagn 1990; 20(4):247-250

6 Foster-Smith K, Garratt KN, Holmes DR Jr. Guidewire transection during rotational coronary atherectomy due to guide catheter dislodgement and wire kinking. Cathet Cardiovasc Diagn 1995; 35(3):224-227

7 Brilakis ES, Best PJ, Elesber AA, et al. Incidence, retrieval methods, and outcomes of stent loss during percutaneous coronary intervention: a large single-center experience. Catheter Cardiovasc Interv 2005;66(3):333-340

8 Gabelmann A, Kramer S, Gorich J. Percutaneous retrieval of lost or misplaced intravascular objects. AJR Am J Roentgenol 2001; 176(6):1509-1513
9 Kim MH, Cha KS, Kim JS. Retrieval of dislodged and disfigured transradially delivered coronary stent: report on a case using forcep and antegrade brachial sheath insertion. Catheter Cardiovasc Interv 2001;52(4):489-491

10 Rozenman Y, Burstein M, Hasin Y, Gotsman MS. Retrieval of occluding unexpanded Palmaz-Schatz stent from a saphenous aorto-coronary vein graft. Cathet Cardiovasc Diagn 1995;34(2):159-161

11 Antonellis IP, Patsilnakos SP, Pamboukas CA, et al. Successful withdrawal from the right coronary artery of an NIR stent dislodged from the balloon catheter. J Interv Cardiol 1999; $3: 215-218$

12 Seong CK, Kim YJ, Chung JW, et al. Tubular foreign body or stent: safe retrieval or repositioning using the coaxial snare technique. Korean J Radiol 2002;3(1):30-37

13 Madronero JL, Hein F, Bergbauer M. Removal of a ruptured, detached, and entrapped angioplasty balloon after coronary stenting. J Invasive Cardiol 2000;12(2):102-104 